\title{
Alicia C. Montoya, Medievalist Enlightenment from Charles Perrault to Jean-Jacques Rousseau
}

Jean-Paul De Nola

\section{(2) OpenEdition}

1 Journals

\section{Édition électronique}

URL : http://journals.openedition.org/studifrancesi/2152

DOI : 10.4000/studifrancesi.2152

ISSN : 2421-5856

Éditeur

Rosenberg \& Sellier

\section{Édition imprimée}

Date de publication : 1 avril 2014

Pagination : 143

ISSN : 0039-2944

\section{Référence électronique}

Jean-Paul De Nola, « Alicia C. Montoya, Medievalist Enlightenment from Charles Perrault to Jean-Jacques Rousseau », Studi Francesi [En ligne], 172 (LVIII | I) | 2014, mis en ligne le 01 avril 2014, consulté le 18 septembre 2020. URL : http://journals.openedition.org/studifrancesi/2152 ; DOI : https://doi.org/ 10.4000/studifrancesi.2152

Ce document a été généré automatiquement le 18 septembre 2020.

\section{(c) $($ ) $\odot$}

Studi Francesi è distribuita con Licenza Creative Commons Attribuzione - Non commerciale - Non opere derivate 4.0 Internazionale. 


\title{
Alicia C. Montoya, Medievalist Enlightenment from Charles Perrault to Jean-Jacques Rousseau
}

\author{
Jean-Paul De Nola
}

\section{RÉFÉRENCE}

ALICIA C. MONTOYA, Medievalist Enlightenment from Charles Perrault to Jean-Jacques Rousseau.

Cambridge, D.S. Brewer, 2013, pp. VIII-248.

1 Les "ténèbres" - "the darkness" - du Moyen Âge continuent à pâtir d'un préjugé défavorable, malgré les lances rompues en leur faveur dès 1943 par Gustave Cohen dans La grande clarté $d u$ Moyen âge. Le Siècle des Lumières en a toujours constitué la resplendissante antithèse. Mais Mme Alicia $C$. Montoya ne perd pas de vue une ligne lumineuse qui, partie du haut Moyen Âge, traverserait les siècles pour aboutir à l'âge philosophique, dans l'attente de la spectaculaire revalorisation de l'époque sombre sous l'égide du romantisme.

2 Cette ligne lumineuse avait déjà été perçue par M. Nathan Edelman (Attitudes of Seventeenth-Century France towards the Middle age, 1946) pour la période 1680-1690 et par M. Lionel Gossman (Medievalism and the Ideologues of the Enlightenment, 1968) pour les décennies 1740-1789. On aura remarqué que ces spécialistes font commencer le Siècle des Lumières vers 1680 , ce qui n'est pas déraisonnable, puisque Bayle et Fontenelle naissent et œuvrent dans la seconde moitié du XVII ${ }^{\mathrm{e}}$ siècle et que la Querelle des Anciens et des Modernes ainsi que «la crise de la conscience européenne» éclatent à la même époque. Il subsistait un gap, une lacune chronologique entre 1690 et 1740 , que Mme Montoya s'est chargée de remplir.

Certes, la littérature des siècles moyenâgeux n'était pas tout à fait oubliée à l'époque des Encyclopédistes. Les bons esprits appréciaient les chansons de geste et François Villon, la Farce de Maître Pathelin et le Roman de la Rose. Et de nouveaux genres littéraires 
ne tardent pas à naître, s'inspirant de sources médiévales: le roman épistolaire, dans le sillage des lettres d'Héloïse et Abélard, les contes de fées (fairy tales), qui se réfèrent à des origines moyenâgeuses vraies ou inventées, l'opéra (ou tragédie lyrique), qui renoue avec les romans de chevalerie. Il faut préciser ici un problème de terminologie. Ce qu'on appelait «nos vieux romans» ou «nos romans de chevalerie» correspond en anglais à romances, plus précisément chivalric romances, tandis que le «roman» en français moderne - à partir de La Princesse de Clèves - se dit novel au-delà de la Manche. Notre «nouvelle» devient short story pour les anglophones. Et la «romance» française? Aux $\mathrm{XVIII}^{\mathrm{e}}$ et $\mathrm{XIX}^{\mathrm{e}}$ siècles ce sera, selon le Robert, "une pièce poétique simple, assez populaire, sur un sujet sentimental et attendrissant». Même terme et même signification dans la langue de Shakespeare.

4 Toujours dans le domaine du médiévalisme au XVIII siècle il convient de mentionner les études érudites qui étaient liées surtout à l'Académie des Inscriptions et Belles-Lettres, cette sœur cadette de l'Académie française. La Curne de Sainte-Palaye, le comte de Caylus et le baron de Montesquieu étaient particulièrement actifs.

Battue en brèche la théorie de la perfectibilité chronologique - le Siècle philosophique est supérieur à toutes les époques précédentes, puisqu'il leur est postérieur -, le mythe $\mathrm{du}$ «bon vieux temps» commence à se faire jour, en littérature aussi bien qu'en amour: «on n'aime plus comme on aimait jadis». Le Moyen Âge fut peut-être un «âge d'or» et ses chefs-d'œuvre littéraires s'élèvent alors au niveau de «classiques modernes» dignes des classiques gréco-latins. Ces conceptions sont scrupuleusement examinées par l'auteure de ce livre dense et touffu, depuis le Parallele des Anciens et des Modernes de Charles Perrault jusqu'à Julie ou la Nouvelle Héloïse. 